\title{
Lung transplantation in Kartagener syndrome and situs inversus: Potential of multidetector row computed tomography and three-dimensional postprocessing
}

\author{
Thomas Schertler, Dr med, ${ }^{a}$ Didier Lardinois, PD, Dr med, ${ }^{\mathrm{b}}$ Thomas Boehm, PD, Dr med, ${ }^{a}$ Walter Weder, Prof, Dr med, ${ }^{\mathrm{b}}$
} Simon Wildermuth, PD, Dr med, ${ }^{a}$ and Hatem Alkadhi, PD, Dr med, ${ }^{a}$ Zurich, Switzerland

$\mathrm{K}$ artagener syndrome is a rare congenital genetic disorder that is characterized by the triad situs inversus, bronchiectasis, and sinusitis. ${ }^{1}$ Patients have defective ciliary motility that leads to reduced or absent mucus clearance in the lungs and susceptibility to chronic respiratory infections. Lung transplantation has been shown to be effective in cases of severe respiratory failure. Only a few cases of lung transplantation in patients with Kartagener syndrome have been reported so far. ${ }^{2}$

Multidetector row computed tomography (MDCT) represents the principal diagnostic modality for the assessment of bronchopulmonary and cardiovascular anatomy. Recent developments of MDCT technology, including CT angiography (CTA), enable the acquisition of near-isotropic datasets representing the prerequisite for 2- and 3-dimensional (2D and 3D) postprocessing techniques.

We describe the case of a patient with Kartagener syndrome in whom MDCT with 2D and 3D postprocessing allowed a precise visualization of bronchopulmonary and cardiovascular morphologic characteristics before and after lung transplantation.

\section{Clinical Summary}

The diagnosis of Kartagener syndrome with situs inversus totalis thoracalis et abdominalis was made in a 59-year-old patient at the age of 19 years. At the age of 13 years, a lower bilobectomy (middle and lower lobes) was performed on the left side because of symptomatic bronchiectasis. In recent years, the patient had global respiratory insufficiency. Bilateral lung transplantation was planned.

Preoperative MDCT was performed for surgical treatment planning, and images were postprocessed with multiplanar reformations (MPR), surface-shaded display (SSD), and volume rendering (VR) technique. The CT showed dextrocardia, a right-sided

\footnotetext{
From the Institute of Diagnostic Radiology a and the Division of Thoracic Surgery, Department of Surgery, ${ }^{\mathrm{b}}$ University Hospital Zurich, Switzerland.

This study was supported by the National Center of Competence in Research, Computer Aided and Image Guided Medical Interventions of the Swiss National Science Foundation.

Received for publication March 23, 2007; revisions received May 8, 2007; accepted for publication May 11, 2007.

Address for reprints: Dr med Thomas Schertler, Institute of Diagnostic Radiology, University Hospital Zurich, Raemistrasse 100, CH-8091 Zurich, Switzerland. (E-mail: thomas.schertler@usz.ch)

J Thorac Cardiovasc Surg 2007;134:814-5

$0022-5223 / \$ 32.00$

Copyright (C) 2007 by The American Association for Thoracic Surgery doi:10.1016/j.jtcvs.2007.05.013
}

ascending aorta and aortic arch, and multiple bronchiectasis in the (right) lingula and left upper lobe (Figure 1). Furthermore, the preoperative CT scan revealed the direction and exact length of the main stem bronchi for facilitating surgical planning. Virtual bronchoscopic images using the SSD and VR techniques revealed an irregularly shaped distal trachea and the bronchial stump after left middle and lower lobe resection (Figure 1).

Lung transplantation was performed 8 months after the patient had been put on the waiting list. For the sequential bilateral lung transplantation, a clamshell approach (combination of two anterolateral thoracotomies with a transverse sternotomy) was chosen. This access was used to provide optimal exposure in this patient with situs inversus. Extracorporeal circulation was not required. The left donor lung was first transplanted on the left recipient side and then the right donor lung on the right recipient side. Postoperative recovery was uneventful. VR combined with CTA images demonstrated a kinking of the right pulmonary artery without hemodynamically relevant stenosis (Figure 2).

\section{Discussion}

Kartagener syndrome increases the propensity for chronic infections at multiple sites along the respiratory tract and this contributes, ultimately, to end-stage pulmonary failure. Combined heartlung transplantation has been introduced as an effective treatment modality. This procedure is performed in a limited number of patients because the low probability of finding a suitable donor with situs inversus, and the absence of situs solitus imposes major surgical difficulties. ${ }^{2}$ Double-lung transplantation offers the potential advantages of preserving the native heart, thereby optimizing the organ's use and allowing a shorter lung ischemic time. ${ }^{3} \mathrm{We}$ performed a modification of the surgical technique of sequential single-lung transplantation. The left atrial and pulmonary artery anastomoses were similar to those observed in patients with situs solitus; the inverse direction and length of the main stem bronchi were easily correctable and adaptable to the anatomy of the patient.

This case illustrates the potential of MDCT using dedicated postprocessing techniques for surgical treatment planning and postoperative surveillance in a patient with Kartagener syndrome. MDCT allows the demonstration of complex anatomic relationships necessary to plan complex surgical procedures and to visualize the particular structural-vascular relationship after surgery. ${ }^{4}$ Virtual bronchoscopy is a recently developed, well-established 3D technique that renders axial CT data into simulated endobronchial views and has an excellent correlation to standard endoscopic procedures. ${ }^{5}$ The $2 \mathrm{D}$ and $3 \mathrm{D}$ imaging techniques give an even better visual understanding of the anatomy than pure endoluminal procedures such as bronchoscopy or catheter angiography. 

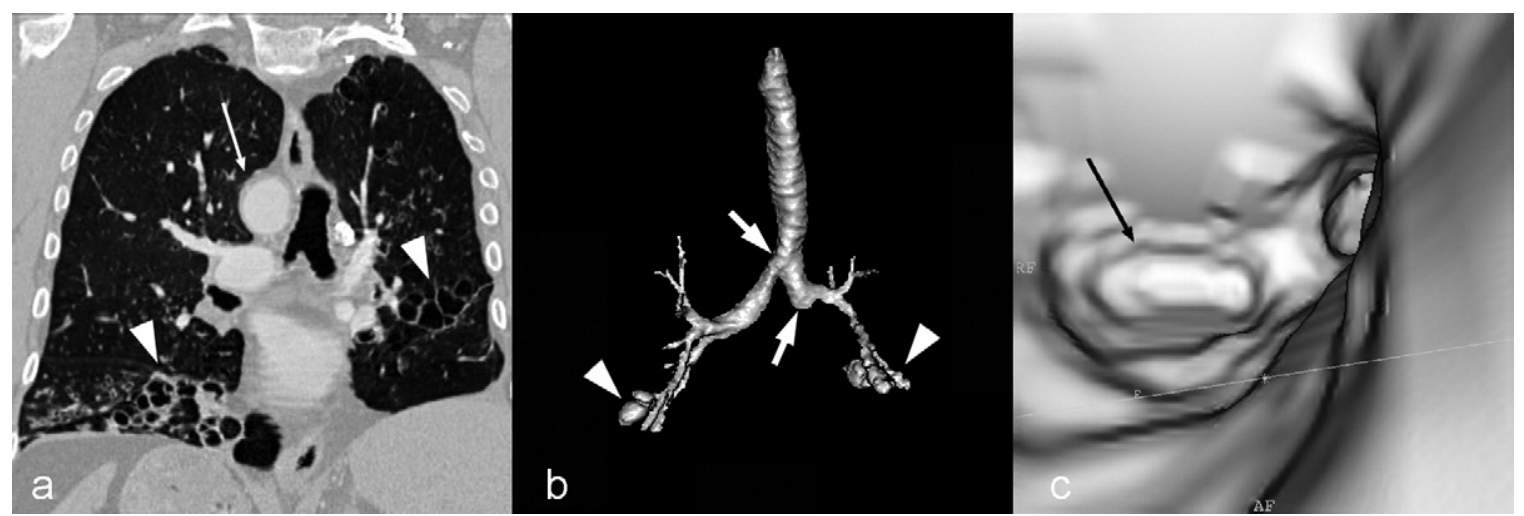

Figure 1. Preoperative CT-based coronal MPR (a) and SSD of the bronchial tree (b). Situs inversus with dextroposition of the ascending aorta and aortic arch (arrow) (a). Multiple bronchiectasis (arrowheads) in the (right) lingula and left upper lobe after previous middle lobe and lower lobe resection on the left side (a, b). Irregular shaped distal trachea with a low-grade carinal stenosis and a sacculation of the left main bronchus corresponding to the stump after left lobectomy (arrows) (b). SSD furthermore revealed the exact geometry and length of the main stem bronchi, facilitating surgical planning (b). Endobronchial view (c) based on virtual bronchoscopy of MDCT data of the left main bronchus and bronchial stump (arrow) of the resected left lower lung segments. MPR, multiplanar reformations; SSD, surface-shaded display; MDCT, multidetector row computed tomography.

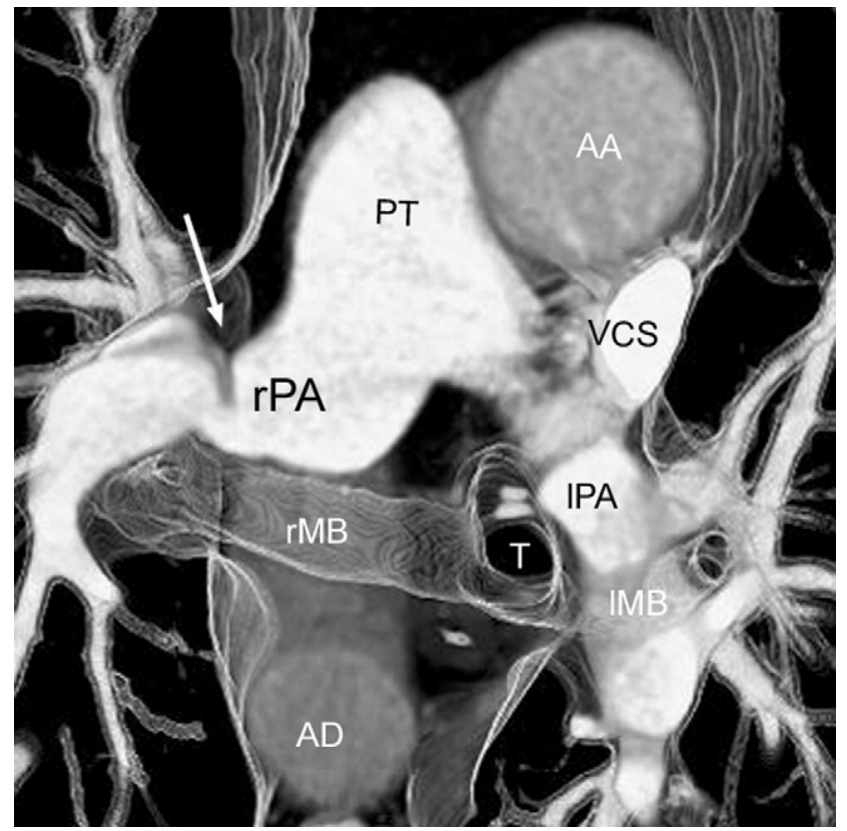

Figure 2. Postoperative situs after lung transplantation demonstrating bronchial and cardiovascular anatomy. VR image in a caudocranial view demonstrates a kinking (white arrow) of the right pulmonary artery (rPA). The kinking had no impact on the clinical condition. $A A$, Ascending aorta; $A D$, descending aorta; $P T$, pulmonary trunk; IPA, left pulmonary artery; $T$, trachea; $r M B$, right main bronchus; IMB, left main bronchus; VR, volume rendering.
In conclusion, we have presented the potential of MDCT with $2 \mathrm{D}$ and $3 \mathrm{D}$ postprocessing techniques for the preoperative evaluation and postoperative surveillance in a patient with Kartagener syndrome. The sometimes limited view obtained at the time of surgery can be compensated by complete $2 \mathrm{D}$ and $3 \mathrm{D}$ representations of MDCT data to help the surgeon mentally reconstruct the view in a realistic way. In addition, using the most advanced imaging techniques in planning treatment strategies for patients requiring thoracic surgery may act as a multiplier to develop new procedures.

\section{References}

1. Kartagener M. [Bronchiectasis in visceral situs inversus]. Praxis. 1968; 57:622-3.

2. Macchiarini P, Chapelier A, Vouhe P, Cerrina J, Ladurie FL, Parquin F, et al. Double lung transplantation in situs inversus with Kartagener's syndrome. Paris-Sud University Lung Transplant Group. J Thorac Cardiovasc Surg. 1994;108:86-91.

3. Patterson GA, Cooper JD, Goldman B, Weisel RD, Pearson FG, Waters $\mathrm{PF}$, et al. Technique of successful clinical double-lung transplantation. Ann Thorac Surg. 1988;45:626-33.

4. McAdams HP, Palmer SM, Erasmus JJ, Patz EF, Connolly JE, Goodman PC, et al. Bronchial anastomotic complications in lung transplant recipients: virtual bronchoscopy for noninvasive assessment. Radiology. 1998;209:689-95.

5. Higgins WE, Ramaswamy K, Swift RD, McLennan G, Hoffman EA. Virtual bronchoscopy for three-dimensional pulmonary image assessment: state of the art and future needs. Radiographics. 1998;18: $761-78$. 